\title{
Evaluation of Teaching and Learning Attitude and the Perception of 2nd M.B.B.S Medical Students in Pathology Classrooms - A Survey- Based Study
}

\author{
Krishnamurthy B ${ }^{1 *}$, Anuradha B ${ }^{2}$, Chandrasekhar BHP ${ }^{3}$, Nagendraprasad D ${ }^{4}$ \\ ${ }^{1,3,4}$ Assistant Professor, Department of Pathology, S.V. Medical College, Tirupati, Andhra Pradesh, India \\ ${ }^{2}$ Professor and HOD, Department of Pathology, S.V. Medical College, Tirupati, Andhra Pradesh, India
}

\author{
DOI: 1 10.36348/sjpm.2020.v05i02.019 $\quad$ | Received: 18.02 .2020 | Accepted: 25.02 .2020 | Published: 29.02 .2020 \\ *Corresponding author: Dr. B. Krishnamurthy M.D, D.D.V.L
}

\section{Abstract}

Background: Pathology is considered by 2nd-year MBBS medical students to be an interesting and useful but most difficult subject. The problems of memorizing and volatility of the subject faced by the students can be tackled by making them learn by putting them in a particular situation and giving them a task as a source of learning, comparable to an actual task that he may face in his future professional life, addressed to as "Problem-based learning" (PBL). Methods: The Cross-sectional study was carried in Narayana medical college, Nellore. The participants were 150 2nd MBBS students (regular batch) who have completed $3^{\text {rd }}$ semesters of pathology. Data were collected at the end of 3 semesters of pathology using a predesigned questionnaire. Data entry and analysis was done using Microsoft Excel. Percentages were used to analyze the data. Results: A total of 150 students (regular batch) who were going to appear for the 2nd MBBS university exams participated in our study. All of them returned the completed questionnaire. Of the $150,88 \%$ were female students, and $12 \%$ were male students. A vast majority of the students, $98 \%$, found pathology to be an interesting subject. The majority of the students, $80 \%$ were satisfied with the content of the lectures taken and only $12.5 \%$, felt otherwise. Blackboard teaching (87\%). Conclusion: The study showed that most students had a positive attitude towards pathology. Students are in favor of the use of blackboard teaching, PowerPoint presentations, case-based discussions and integrated teaching.

Keywords: Pathology, teaching, learning, attitude, perception, M.B.B.S medical students.

Copyright @ 2020: This is an open-access article distributed under the terms of the Creative Commons Attribution license which permits unrestricted use, distribution, and reproduction in any medium for non-commercial use (NonCommercial, or CC-BY-NC) provided the original author and sources are credited.

\section{INTRODUCTION}

It cannot be emphasized enough that a solid understanding of pathology is the foundation for good clinical practice and Pathology being a vast subject with the number of lecture hours being limited, understanding the students' perspective is essential for generating interest in the subject and for gaining essential knowledge and skills during those limited hours assigned [1].

The second MBBS is a crucial period in undergraduate education because this is when the student is initiated into clinical postings and taught the etiology and pathogenesis of various disease processes. Pathology ridges the gap between basic sciences and clinical medicine, and this subject is essential because a proper understanding of pathological processes is vitally essential for medical practice [2].
The main goals of undergraduate pathology teaching have always been to provide a framework for the description of the disease and to provide students with knowledge of the functional and structural changes in the condition so that clinical signs and symptoms can be understood and interpreted. With pathology teaching hours have decreased over the years; this is a problematic aim that requires excellent planning. The balancing of teaching hours with the available faculty and student motivation is a significant difficulty for the victorious general improvement of the curricula student [3].

The Medical Council of India has arranged medical faculties training through the organization of medical education units in all medical colleges. Medical education units conduct regular sessions throughout the region. 
Receiving feedback from the students regarding teaching methodology is a crucial part of any teaching. So present study was carried out to evaluation of teaching and learning attitude and the perception of 2nd M.B.B.S medical students in pathology classrooms - A survey-based study

\section{METHODS}

The present study was a cross-sectional study; this study was carried in Narayana medical college, Nellore. The participants were 150 2nd MBBS students (regular batch) who have completed $3^{\text {rd }}$ semesters of pathology. 2nd-year MBBS students who have completed 3 semesters in Pathology teaching and were going to appear for their university exams having more than $75 \%$ attendance were included from the study. Repeaters and supplementary batch students were excluded from this study. Students with less than $75 \%$ attendance were also excluded from the study. A predesigned, structured, pre-validated questionnaire after peer review was used to gather information regarding student's attitude and perception of pathology and about the various teaching-learning methods currently used by the faculty. The questionnaire included 17 questions and space was also provided for any suggestions or changes recommended. Data entry and analysis was done using Microsoft Excel. Percentages were used to analyze the data.

\section{RESULTS}

Table-1: Students' perception of pathology as a subject.

\begin{tabular}{|l|l|l|l|l|}
\hline S. No & Questions & Yes (\%) & No (\%) & $\begin{array}{l}\text { Don't } \\
\text { Know (\%) }\end{array}$ \\
\hline 1 & Do you find pathology interesting? & $98 \%$ & $2 \%$ & $0 \%$ \\
\hline 2 & Does a sound knowledge of pathology help in clinical posting? & $97 \%$ & $1 \%$ & $2 \%$ \\
\hline 3 & $\begin{array}{l}\text { Does the integration of pathology teaching with clinical subjects } \\
\text { help in a better understanding of disease concepts? }\end{array}$ & $97.5 \%$ & $0 \%$ & $2.5 \%$ \\
\hline 4 & Is general pathology more difficult than systemic pathology? & 23.7 & $72.3 \%$ & $4 \%$ \\
\hline
\end{tabular}

A total of 150 students (regular batch) who were going to appear for the 2nd MBBS university exams participated in our study.

All of them returned the completed questionnaire. Of the $150,88 \%$ were female students and $12 \%$ were male students.

A vast majority of the students, $98 \%$, found pathology to be an interesting subject. $97 \%$ of them agreed that a sound knowledge of pathology was useful during their clinical postings and for their clinical practice in the future. $97.5 \%$ were of opinion that an integrated model of teaching pathology along with other clinical specialty subjects would help in a better understanding of various diseases. $72.3 \%$ of the students found systemic pathology to be more difficult than general pathology, while $23.7 \%$ of the students felt general pathology was easier than systemic pathology (Table 1).

Table-2: Teaching methodology: content and quality

\begin{tabular}{|c|c|c|c|c|}
\hline S. No & Questions & Yes $(\%)$ & No $(\%)$ & $\begin{array}{l}\text { Don't } \\
\text { Know }(\%)\end{array}$ \\
\hline 1 & Are you satisfied with the content of the lectures? & $80 \%$ & $12.5 \%$ & $7.5 \%$ \\
\hline 2 & $\begin{array}{l}\text { Do you feel that important points have been adequately } \\
\text { highlighted during lectures and practical classes? }\end{array}$ & $96 \%$ & $0 \%$ & $4 \%$ \\
\hline 3 & $\begin{array}{l}\text { Are you satisfied with the explanations given during lectures and } \\
\text { practical classes? }\end{array}$ & $73 \%$ & $12 \%$ & $5 \%$ \\
\hline 4 & Are you satisfied with the delivery and pace of the lectures? & $70.5 \%$ & $19 \%$ & $10.5 \%$ \\
\hline 5 & $\begin{array}{l}\text { Are you encouraged to ask questions and give answers during the } \\
\text { classes? }\end{array}$ & $74 \%$ & $13 \%$ & $13 \%$ \\
\hline 6 & Are the number of classes taken in pathology adequate? & $89.2 \%$ & $6.3 \%$ & $4.5 \%$ \\
\hline 7 & Are the duration of each of the classes adequate? & $83 \%$ & $10.7 \%$ & $6.3 \%$ \\
\hline
\end{tabular}

The majority of the students, $80 \%$ were satisfied with the content of the lectures taken and only $12.5 \%$ felt otherwise. $9.2 \%$ felt that the number of lectures taken on each topic was adequate, while only $6.3 \%$ felt this was inadequate, $83 \%$ felt that a duration of 1 hour per lecture was adequate. $96 \%$ of them felt that enough stress had been laid important topics during the lecture classes and important points have been highlighted adequately.73\% of the students were satisfied with the explanations given while clarifying doubts asked during the lectures. $70.5 \%$ said that they were satisfied with the style of delivery and pace of the lectures, while $19 \%$ said they were not. $74 \%$ said that they were encouraged to ask and answer questions during the lectures and practical classes (Table 2). 
Table-3: Teaching tools

\begin{tabular}{|l|l|l|l|l|}
\hline S. No & Questions & Yes (\%) & No (\%) & $\begin{array}{l}\text { Don't } \\
\text { Know (\%) }\end{array}$ \\
\hline 1 & Is the displayed lecture material easy to follow and satisfactory? & $81 \%$ & $9 \%$ & $10 \%$ \\
\hline 2 & $\begin{array}{l}\text { Are the images, flow charts, and graphics used during the } \\
\text { lectures relevant to the topic? }\end{array}$ & $92.6 \%$ & $4.2 \%$ & $3.2 \%$ \\
\hline 3 & Are these following kinds of teaching-learning methods useful for learning and understanding pathology? \\
\hline a & Black board teaching & $87 \%$ & $6.3 \%$ & $6.7 \%$ \\
\hline b & Powerpoint presentations & $81.8 \%$ & $10.2 \%$ & $8 \%$ \\
\hline c & $\begin{array}{l}\text { case based discussions and group } \\
\text { discussions }\end{array}$ & $97 \%$ & $0 \%$ & $3 \%$ \\
\hline d & Integrated teaching & $80 \%$ & $11.8 \%$ & $8.2 \%$ \\
\hline e & Pathology museum & $65 \%$ & $25 \%$ & $10 \%$ \\
\hline f & Seminars and symposium & $67 \%$ & $20.6 \%$ & $12.4 \%$ \\
\hline g & quizzes & $61 \%$ & $37.7 \%$ & $1.3 \%$ \\
\hline
\end{tabular}

Regarding the teaching-learning tools employed for pathology classes, the majority (81.8\%) agreed that PowerPoint presentation was very useful in teaching and understanding pathology. Other popular modes were case-based discussions and group discussion (97\%), blackboard teaching $(87 \%)$ and integrated teaching $(80 \%)$. Quizzes, seminars \& symposiums and use of the departmental museum were perceived by the students as least useful in studying and understanding pathology. Most of the students, $81 \%$, agreed that the lectures and practical classes highlighted concepts in an easy to follow manner and with good legibility. $92.6 \%$ also agreed that images, flowcharts and graphics that were used during the course of the lectures were relevant to the topic and useful for understanding the topic (Table 3).

Table-4: Modes of assessment

\begin{tabular}{|l|l|l|l|l|}
\hline S. No & Questions & Yes (\%) & No (\%) & Don't Know (\%) \\
\hline \multicolumn{1}{|l|}{ Are the following modes of assessment helpful in improving knowledge and application skills? } \\
\hline 1 & Written exams & $97.2 \%$ & $2.8 \%$ & $0 \%$ \\
\hline 2 & Viva voce & $92 \%$ & $8 \%$ & $0 \%$ \\
\hline 3 & Practical exams & $91 \%$ & $7 \%$ & $2 \%$ \\
\hline
\end{tabular}

Regarding the modes employed for assessment of the students, 97.2 of the students agreed that written exams were a very effective assessment tool. $92 \%$ felt viva and $91 \%$ felt practical exams were also a useful tool in assessing the knowledge of the students, while only $8 \%$ felt viva was not useful in the assessment of knowledge and application skills of the students (Table 4).

Among the changes suggested by the students, the point most mentioned was that more practical exams and monthly tests need to be conducted because pathology was perceived as a vast subject. Lack of effective teacher-student communication was also mentioned in $7 \%$ of the feedback forms.

\section{DISCUSSION}

In the present study, all the $150(100 \%)$ 2nd MBBS students responded to the questionnaire. Female students outnumbered the male students in our study in the ratio 22:3. This was similar to the study conducted by Quadri et al.[4] and Vijayan P[5].

In our study, we found that most students had a positive attitude towards pathology with most agreeing that a sound knowledge of pathology was useful for their clinical practice in the future. An integrated model of teaching pathology long with other clinical specialty subjects was preferred by a majority of students as they felt it helps in a better understanding of various disease processes.

The study by Rafique $\mathrm{N}^{6}$ showed integrated teaching is effective in enhancing the skill of clinicopathological correlation and helps to improve the cognitive and psychomotor domains of the students.

Similar findings were observed by Manoj[7], they found it difficult to synchronize and integrate the different subjects. They found tutorials and group discussions more useful than lectures and seminars and suggested to cut short the duration of the lecture. They advocated the judicious use of powerpoint along with the conventional method of teaching. They wanted some multiple-choice questions to be included in the tests and in the final exams. They wanted some sessions on career counseling and wished the effective implementation of the mentoring system.

Most of the students were satisfied with the content \& quality of lectures, duration and number of lectures, the stress laid on important points and explanations given by the faculty while clarifying doubts. 
Most of the students agreed that case-based discussion and group discussions, the use of Powerpoint presentations during lectures and integrated teachings are the most effective modes of teaching-learning.

Another important point mentioned by $7 \%$ of the students was a lack of student-teacher interaction. This could be because of the lack of a student mentoring program by faculty in our institution. This can be addressed by assigning a small group of students to one faculty in the department so that the faculty takes on the role of a mentor to that group of students. This will help in answering questions, giving advice, listening to the student's problems and difficulties and stimulating reflection.

\section{CONCLUSION}

The study showed that most students had a positive attitude towards pathology. Students are in favor of the use of blackboard teaching, PowerPoint presentations, case-based discussions and integrated teaching.

\section{REFERENCES}

1. Shah, A., Shethwala, N., Parmar, B. (2014). Perception of undergraduate medical students towards the subject of pathology at one of the Medical Colleges of Gujarat, India. International Journal of Medical Science andPublic Health, $3(7): 863$.
2. Domizio, P. (2006). 12 The Changing Role of Pathology in the Undergraduate Curriculum. In: Hall PA, WrightNA, editors. Understanding Disease: A centenary celebration of the Pathological Society. London: Wiley, 137-52.

3. Dick, F., Leaven, T., Dillman, D., Torner, R., Finken, L. (1998). Core morphological concepts of disease for second-year medical students. Hum Pathol, 29(9):1017-20.

4. Quadri, S., Srujana, S., Mahesh, S., Bheeshma, B. (2016). Undergraduate medical students' feedback and perceptions on teaching-learning methodology in Pathology at Government Medical College. International archives of integrated medicine, 3(7): 28-35.

5. Vijayan, P., Ponniah, A. (2017). A survey study based on undergraduate medical students' feedback regarding pathology and the teaching-learning methodologies employed. Trop J Path Micro, 3(2):149-154.

6. Rafique, N. (2009). Introducing integrated practical examination for 2nd-year MBBS class. 7th GCC Medical Colleges Conference. Dammam, Saudi Arabia: Saudi Society of Family and Community Medicine.

7. Dr. Manoj, G., Dr. Monika, B., Dr. Anshu, G., Dr. Shailesh, Y.(2010). Perceptions and suggestions of 2nd professional MBBS students about their teaching and learning process: An analytical study. NJIRM, 1(4), 20- 4. 